\title{
Salud y migración centroamericana en la frontera sur de Méxicor
}

En la frontera sur de México ocurre prácticamente toda la diversa variedad de tipos de desplazamientos que contiene el catálogo actual de las migraciones internacionales; por origen-destino: surnorte-, norte-sur, campo-ciudad, campo-campo, ciudad-ciudad; por tipo de migración: individual, familiar, comunal; por género: de hombres y mujeres; por periodicidad: diaria, cíclica, temporal, de larga duración; por naturaleza de la migración: económica, política, de refugio, sociocultural; por antigüedad: de flujos viejos y flujos nuevos; por escolaridad y lengua: alfabetos y de masas analfabetas, monolingües (de alguna lengua indígena) o bilingües (que incluye el español); por adscripción económica: con prácticas de subsistencia marginales a la economía de mercado y otros insertos en ella, así como de sectores instruidos y algunos altamente capacitados y funcionales a la productividad económica; por lugar de destino: con destino inmediato a la propia zona fronteriza, con el propósito de mayor internación o de transmigración a un tercer país; por el medio utilizado en la migración: traslado a pie, por caminos vecinales, en transporte público terrestre, en ferrocarril, por aire o por embarcaciones marítimas menores; por existencia $o$ ausencia de red social de apoyo: con más o menos organización y asistencia; por antecedentes migratorios: con conocimiento o completo desconocimiento de caminos, distancias o entornos sociales, etcétera.

Una porción significativa de estos desplazamientos ocurre de manera indocumentada; las autoridades migratorias de México realizan, desde 1990 , $1,119,000$ expulsiones de extranjeros en promedio anual, y cerca del 97 por ciento proviene de Centroamérica, principalmente de Guatemala, El Salvador, Honduras y Nicaragua.

En el análisis del rubro salud de los centroamericanos en México, o en tránsito por el país, concurren varios factores. En general son los siguientes: (1) características de la población migrante; (2) la oferta de salud pública en sus lugares de origen; (3) la oferta de salud pública en los lugares de destino; (4) aspectos culturales, económicos y sociales del tipo de desarrollo prevaleciente en la región; (5) cuadros epidemiológicos y principales causas de mortalidad en ambos lados de la frontera, y (6) principales causas de morbilidad y mortalidad de los centroamericanos en la frontera sur de México. La conjugación de estos factores permitirán observar que, independientemente del volumen, esta-

1. El autor de este escrito es Rodolfo Casillas, profesor e investigador de la Facultad Latinoamericana de Ciencias Sociales, FLACSO (sede académica de México). También quiere hacer patente su agradecimiento a la Fundación John T. and Catherine D. MacArthur por el financiamiento otorgado para la investigación "Perfil sociodemográfico del transmigrante centroamericano en México, 1989-1996", cuyos primeros resultados alimentan parcialmente el presente texto. 


\section{Cuadro 1}

\section{Expulsiones y rechazos hechos por el Instituto Nacional de Migración de México por nacionalidad que se indica, 1990-1996}

\begin{tabular}{lrrrrrrrr}
\hline Nacionalidad & 1990 & 1991 & 1992 & 1993 & 1994 & 1995 & 1996 & Total \\
\hline Guatemalteca & 58845 & 69991 & 65304 & 58910 & 42961 & 52051 & 50503 & 368565 \\
Salvadoreña & 45598 & 40441 & 26643 & 28646 & 22794 & 19526 & 20903 & 204551 \\
Hondureña & 14954 & 18419 & 25546 & 26734 & 32414 & 27236 & 31041 & 176344 \\
Nicaragüense & 3039 & 1265 & 1682 & 3438 & 12330 & 2513 & 1867 & 26134 \\
Beliceña & 488 & 292 & 2859 & 168 & 273 & 207 & 150 & 4437 \\
Otras & 3516 & 2934 & 1012 & 4109 & 2343 & 4399 & 2632 & 22600 \\
\hline Total & $I 26440$ & 133342 & 123046 & 122005 & 113115 & 105940 & 107096 & 802631 \\
\hline
\end{tabular}

Fuente: Instituto Nacional de Migración, Estadística Migratoria, México, enero, 1997, Dirección General de Investigación y Planeación.

mos en presencia de un fenómeno complejo, escasamente conocido y poco estudiado. Dada la diversidad aludida de flujos y caraterísticas concomitantes, expondremos a continuación sólo un caso, el de los trabajadores agrícolas guatemaltecos, con el propósito de evidenciar la complejidad existente entre movimientos poblacionales y salud.

De acuerdo con el modelo ecológico de análisis de la migración, la etapa inicial de desequilibrio poblacional se produjo por efecto de la saturación del subsistema rural, el crecimiento de la población, el agotamiento de la tierra y la centralización de los recursos en el subsistema urbano. Como consecuencia, la concentración urbana de los servicios públicos y las fuerzas económicas expusieron el campo a la pobreza, la marginación y la violencia social y política, caracierísticas que por cierto no son privativas de las áreas rurales. Si hacemos caso a dicho modelo, habría que decir que el proceso migratorio es, en buena medida, resultado de un desequilibrio ecológico entre el campo y la ciudad. Otro tanto se explicaría por los procesos de urbanización rebasados por el crecimiento social de la población y la consecuente demanda de varios servicios que han estimulado nuevas emigraciones ciudad-ciudad, ciudad-suburbio. Sus características peculiares de- penderán, en todo caso, de las circunstancias de cada caso y cambiarán en el tiempo. En consecuencia, su comprensión debe fundarse en el análisis de cada ecosistema visto como un todo. A la diversidad de situaciones que originan e inciden en la migración internacional, así como las características que ésta adquiere, hay que agregar el limitado conocimiento que se tiene sobre estos flujos migratorios y sus peculiaridades. En este comentario, en consecuencia, planteo un tema escasamente conocido y que, a la luz de la complejidad del fenómeno social que involucra a miles de centroamericanos y a varios países del área y de México, cuando no también a Estados Unidos, es de gran pertinencia para el análisis social y la toma de decisiones de los gobiernos de la región: migración centroamericana y salud ${ }^{2}$.

Caracteristicas de los migrantes y de las actividades en los lugares de destino

Los trabajadores guatemaltecos en México conforman uno de los cuatro flujos migratorios que se presentan en la frontera sur de México ${ }^{3}$. Hasta hace unos 15 años, su presencia era prácticamente percibida sólo por los sectores sociales locales que tenían relación con ellos (empleadores, comerciantes

2. Dada la diversidad de flujos, ilustro el tema a partir del caso de los trabajadores agrícolas que concurren a los campos de cultivo del Soconusco chiapaneco, en la frontera mexicana con Guatemala.

3. Los cuatro flujos migratorios que ocurren en la frontera sur de México son: trabajadores agrícolas, refugiados, transmigrantes y población dispersa. Obviamente, en el interior de estos cuatro flujos se pueden establecer diferenciaciones en cuanto a su naturaleza, magnitud, duración, origen, motivos, condición migratoria, etc. 
e involucrados en el traslado y contratación, así como un reducido sector de las autoridades de migración). Las cosas han cambiado: en los últimos tres quinquenios se observan cambios cualitativos y cuantitativos en los flujos, particularmente en trabajadores ${ }^{4}$, transmigrantes 5 y el surgimiento del flujo de refugiados, sin punto de comparación con los hechos precedentes, lo cual ha llamado la atención de distintos sectores sociales, académicos y gubernamentales debido a la diversificación de los lugares de origen - los de destino, de la temporalidad de la migración, de la composición comunal y familiar, de las rutas migratorias, de la ocupación previa a la migración, etc. Presumiblemente, aunque no existe todavía forma de comprobarlo, también cambios en el volumen.

Los guatemaltecos van al Soconusco chiapaneco a los cultivos de café, caña de azúcar y plátano, fundamentalmente. Se estima que el volumen total de trabajadores migrantes oscila entre 80 y $150 \mathrm{mil}$ al año, sin incluir a sus acompañantes (hijos mayores, mujeres y niños). La gran mayoría se dirige al café, y las proporciones menores (no más de $10 \mathrm{mil}$ en total) a los otros dos cultivos. Además, hay que mencionar la existencia de otros grupos de trabajadores domésticos, importante fuerza en el área citadina de la fronteriza Tapachula, Chiapas.

En tanto que el café y el azúcar son actividades estacionales, los flujos se adecuan a su temporalidad; de abril a agosto para las labores de limpia; de septiembre a febrero para la cosecha del café, y de enero a mayo para el corte de caña. El cultivo del plátano es una actividad permanente por lo que los desplazamientos internacionales tienen frecuencias variables: diarias, semanales o varias semanas. Esta variedad en los desplazamientos da una idea de la cercanía y fácil acceso de la comunidad de origen al centro de trabajo, independientemente de los límites fronterizos nacionales y los procedimientos migratorios que pudieran aplicarse.
En términos de salud, tal movilidad gravita en la posibilidad de que los migrantes pueden ser portadores, sin ningún tipo de control, de vectores de una localidad a otra, es decir, de un país a otro. Los efectos de los flujos transfronterizos en la salud de la población pueden ser, por lo menos, de cuatro tipos: (1) las condiciones de salud de la población cambian radicalmente, al grado de ser más parecidas a las del país vecino que a las del propio; (2) estas condiciones son totalmente nuevas y difieren tanto de las del país propio como de las del país vecino; (3) las condiciones sanitarias de ambas poblaciones no se modifican, por lo que sus perfiles de salud son los mismos del país de origen, y (4) debido a una integración sociocultural allende las fronteras jurídicas nacionales, existen cuadros sanitarios similares a lo largo de las poblaciones asentadas en las áreas limítrofes. Por tanto, es muy difícil establecer orígenes de patologías específicas y su recurrencia, debido al frecuente intercambio poblacional que ocurre en los espacios físicos involucrados ${ }^{\dagger}$. Como podrá deducirse, estos casos no se presentan de manera pura a lo largo de la lrontera sur de México, sino que pudiera hacerse un estudio más detallado acorde tanto a las características de los flujos migratorios como a los vínculos sociohistóricos que existen entre las comunidades limítrofes de la vasta frontera, con el posible resultado de que un caso se presente en una región y otro en otra. Aquí, por razones de espacio e información disponible, se presentará un caso a manera de ilustración del fenómeno migratorio y sus relaciones con la salud.

Cabe señalar que a lo largo de la frontera nacional de Guatemala con el estado mexicano de Chiapas $(985 \mathrm{~km})$, existe infinidad de caminos vecinales en medio de una vegetación exuberante y de fincas agrícolas que terminan justo en la línea fronteriza. Esto dificulta tanto el control migratorio, las estimaciones sobre el volumen $y$, sin duda, la pues-

4. El Instituto Nacional de Migración (INM) en fecha reciente, mayo de 1997, reconocía que anualmente ingresaban a México 100,000 trabajadores agrícolas, sin hacer estimación alguna sobre el volumen de trabajadores indocumentados.

5. Las expulsiones de indocumentados que hace el Instituto Nacional de Migración, casi en su totalidad, se circunscriben a transmigrantes.

6. Para un mayor desarrollo del tema, ver Casillas R. y López, S. "Un acertijo de nuestros días: esquemas de salud para poblaciones migrantes", versión final de la ponencia presentada en el IV Congreso Latinoamericano de Ciencias Sociales y Medicina, Cocoyoc, México, junio, 1997. 
ta en práctica de programas institucionales de salud para la población migrante.

Particularmente en el cultivo de café $\tilde{f}^{7}$ se presenta una migración colectiva (familiar o comunal); al menos en el 50 por ciento de los casos la encabezan los hombres o jefes de familia y se acompañan de la esposa o los hijos mayores. Su estadía promedio es de seis a ocho semanas y se estima que durante ese lapso la mayoría sólo trabaja en una sola plantación; con baja frecuencia en desplazamientos posteriores a fincas con cultivo similar, y todavía con menor frecuencia en otro tipo de cultivos debido a las tareas especializadas de cada uno. En términos de salud, ello significa que, de contagiarse de algún virus, podrían transportarlo a su lugar de origen y por su ruta migratoria de retorno, más dificilmente lo propagarían de manera directa en otras plantaciones mexicanas de cultivo diferente al que ellos acuden.

En la caña y el plátano, la migración laboral es mayoritariamente individual, con presencia menor de mujeres e infantes de procedencia centroamericana. En parte se debe a las características propias de los cultivos y también a las condiciones de vida en los albergues, sin dejar de considerar que en estos cultivos, la fuerza laboral la constituyen jornaleros del campo con menor apego a formas colectivas de relación con la tierra y las labores agrícolas. De ahí que pueda hacerse una diferenciación de los lugares de procedencia: para el café provienen del altiplano, y para la caña y plátano, de la costa sur, guatemaltecos principalmente. No obstante lo anterior, en los últimos años se empieza a observar una participación creciente de trabajadores procedentes de otros departamentos de Guatemala, incluso sin las habilidades requeridas para algunas tareas especializadas de los cultivos mencionados, lo que incide en una menor productividad, menor salario y mayores riesgos de accidentes de trabajo.

Con respecto a las edad, la mayor proporción se encuentra en las edades más productivas en los tres cultivos (18 a 45 años). Para el corte del café hay presencia significativa de personas de edad avanzada y menores de edad que, al lado del padre, apren- den en el campo el trabajo que algún día deberán hacer de manera independiente o cuando estén al frente de su propia familia. En estas circunstancias de convivencia, las posibilidades de aprendizaje en el trabajo compartido, en la vida compartida en los centros de residencia transitoria, conlleva los riesgos de compartir las enfermedades y los riesgos de accidente laboral; en el trabajo y el descanso, hombres, mujeres y niños forman una fuerza productiva indiferenciable en aras de obtener el máximo ingreso posible.

En todo caso, el ingreso es bajo. Se requiere de una jornada de ocho a diez horas a pleno sol para lograr, en el mejor de los casos, una retribución promedio de aproximadamente tres dólares por día trabajado ${ }^{8}$. Particularmente en el café, el único ingreso monetario que reciben los trabajadores al año es el que devengan como trabajadores temporales en el campo mexicano. El ingreso, por tanto, "debe" ajustar para atender las necesidades más inmediatas, y proporcionar una reserva para los demás gastos que se realicen durante el resto del año en sus lugares habituales de residencia. En el caso del plátano, en la medida que se trata de una actividad permanente, los trabajadores procuran mantenerse en la plantilla de contratados dado que se ha convertido en su único ingreso seguro. Quienes participan en el corte de caña de azúcar, como en el café, el ingreso obtenido en México tiene carácter complementario a la ocupación habitual en su lugar de residencia en Guatemala.

En el corte del café, las relaciones contractuales están mediadas, en un número indeterminado de casos, por el conocimiento previo y la confianza personal entre empleador y empleado. Importan los nexos previos, pues muchos acuden directamente a la unidad productiva en donde los esperan año con año. En consecuencia, no es extraño encontrar ciertos pactos sociales (compadrazgos, etc.) que aseguran la continuidad entre empleados con el paso de las generaciones. Dicho de otra forma, hay vínculos culturales que median las relaciones contractuales. Mientras que para la caña y el plátano el esquema de contratación es diferente, es más impersonal, no se requiere de conocimiento ni relaciones sociales

7. La descripción de flujos y actividades se basa en Casillas, R. y Castillo M.A., Los flujos migratorios internacionales en la frontera sur de México, México, 1994, Secretaría del Trabajo y Previsión Social-Consejo Nacional de Población, p. 248.

8. El ingreso es considerable a la luz de los bajos salarios y la dificultad para encontrar empleo en su natal Guatemala. 
previas y, en ocasiones, media un tercero que les contrata en los lugares de residencia y los dirige durante las labores de corte. Se observa, entonces, una combinación de formas culturales tradicionales y modernas con formas de contratación capitalistas. Esta situación no implica una mejoría sustancial en el salario o las condiciones de vida, o en prestaciones sociales para la población contratada, ni en la posibilidad de que los trabajadores por cuenta propia contraten los servicios médicos particulares en caso de necesitarlo.

En el cultivo del café hay dos tipos de unidades productivas: las propiedades individuales y las colectivas o ejidales. Para el tema que nos ocupa, la diferencia importa en tanto que en las primeras los trabajadores se alojan en galerías o "galleras". En algunos casos, los que acuden en forma familiar tienen la oportunidad de obtener una pequeña casa con un poco más de privacidad; si no es así, van con todos los demás contratados a dormir en el suelo en espacios delimitados con líneas pintadas en el piso de no más de 1.20 por 1.80 metros por personas. En todo caso, el hacinamiento de 100 , 200, 300 trabajadores o más, más acompañantes, crea una situación propicia para la propagación de enfermedades infectocontagiosas de alcances impredecibles. Esto sucede debido a que la estadía y movilidad de grupos que llegan o van ocurre de manera asincrónica, y cuando menos semanalmente durante varios meses.

En cambio, una proporción de trabajadores contratados por ejidatarios, un número reducido es el que puede ser absorbido por este tipo de tenencia, con frecuencia se aloja en las propias viviendas de los empleadores y toma los alimentos preparados por las familias de los mismos sin distingo de habitantes permanentes y temporales. Como cada ejidatario contrata a unos cuantos guatemaltecos, se podría pensar que las condiciones de vida son mejores para los migrantes, lo que no es del todo cierto, como veremos.
Los trabajadores de la caña y del plátano se alojan en albergues con capacidad para 300 trabajadores cada uno; pocos son los que se acompañan de su esposa e hijos, pues el corte es una tarea ruda realizada sólo por hombres. Las condiciones de los dormitorios y el hacinamiento son similares a los de los trabajadores del café; similares también son los riesgos de transmisión de enfermedades. En el caso de las mujeres con hijos empleadas en la producción se observan efectos contraproducentes en el crecimiento de los niños debido a la ocupación materna ${ }^{10}$.

Por concluir con esta caracterización general de los trabajadores guatemaltecos en México, desde una perspectiva que combina lo económico, lo social y lo cultural, se puede decir que se trata de flujos con un pie en formas precapitalistas de socialización, y otro pie en prácticas capitalistas de producción, en los lugares de destino de la migración. Por esta combinación de formas y tradiciones dificilmente pueden ponerse en práctica esquemas de atención a la salud altamente institucionalizados, dado que en contrapartida, por su historia cultural, tipo de relaciones que establecen con sus empleadores y una oferta gubernamental limitada y deficiente (como lo veremos en un momento más) no puede esperarse más que la vigencia de esquemas de sobrevivencia accesibles a las comunidades migrantes, pero que hasta la fecha escapan a cualquier intento de programación y control gubernamentales. De ahí que la atención a la salud de la población de migrantes constituya un desafío de muchos rostros de rasgos imprecisos.

La atención a la salud en Huehuetenango, Guatemala"

Guatemala es un país pobre y más empobrecido en los últimos años. En la actualidad, se estima que cerca del 80 por ciento experimenta algún grado de pobreza. En este contexto, el gasto presupuestal para el rubro social (que incluye salud,

9. Construcción amplia que permite el acomodo masivo de trabajadores, quienes están como pollos y gallinas, de ahí el término de galleras.

10. Takehiro, Misawa e Ixtacuy, Octavio: "El efecto del empleo materno sobre el crecimiento de los ninos según edad de los ninos: la zona de producción platanera en Chiapas", V Reunión Nacional de Investigación Demográfica en México, Sociedad Mexicana de Demografía, 1994.

11. Casillas, R.R. y Vicente M. La frontera sur: un mosaico sanitario, México, Secretaría de Salud, 1994, y CIES: "Perfil epidemiológico y grados de marginación: Chiapas", Cuademo de trabajo, No 1, San Cristóbal de las Casas, Chiapas, Centro de Investigaciones Ecológicas del Sureste, 1994. 


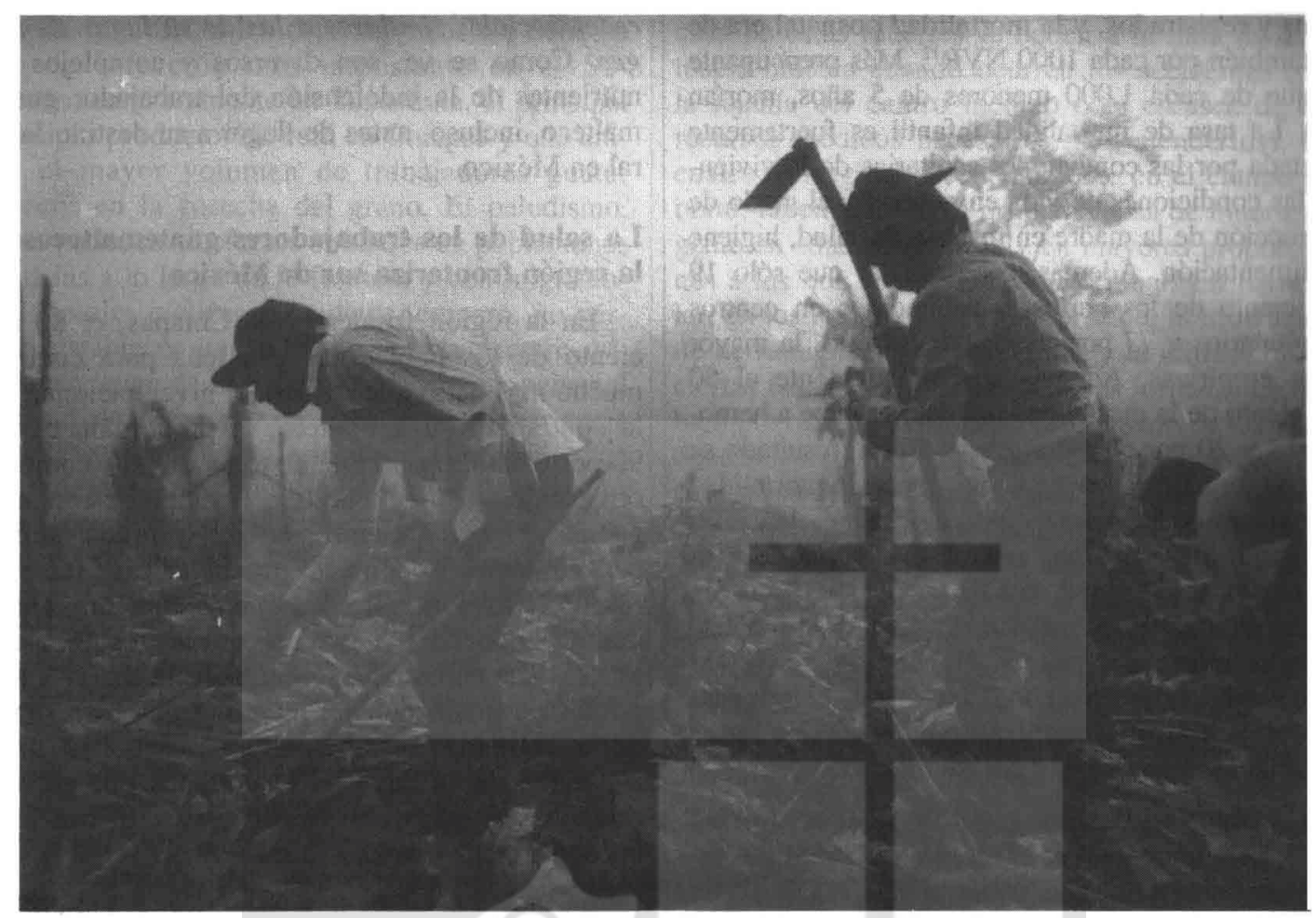

educación y vivienda, entre otras) ha devenido menor en términos reales, a la par de aumentos en la demanda insatisfecha y en el crecimiento poblacional. Cerca del 67 por ciento de la población vive en zonas rurales, con una distribución de 124.4 viviendas por cada 1,000 habitantes, aunque en el campo el hacinamiento es más pronunciado, sin especificarse cifras. El déficit de viviendas y la calidad menor de las existentes se magnífica ante la gran proporción de ellas que no cuentan con los niveles mínimos del provisión de servicios básicos (agua, luz y drenaje). En cuanto a la escolaridad, cerca del 50 por ciento de la población guatemalteca mayor de 15 años es analfabeta, si bien en los sectores rurales e indígenas los porcentajes son mayores: 71 y 77 por ciento, respectivamente.

En lo que respecta al departamento de Huehuetenango, éste es parte de la región más pobre de Guatemala, cuenta con 12 por ciento de la población económicamente activa pero sólo genera 4 por ciento del producto interno bruto. Su población es básicamente campesina e indígena (66 por ciento), tiene distintas ramas mayenses y, aparte del español, se hablan siete idiomas más. Cerca del 45 por ciento es menor de 15 años. En lo que se refiere a los servicios de salud, éstos son proporcionados por dependencias gubernamentales, semiautónomas y no gubernamentales. La oferta de salud gubernamental involucra a cerca de 500 personas, incluyendo 35 médicos, 28 enfermeras profesionales, 44 técnicos varios y 51 empleados para distintas labores administrativas y de mantenimiento de las instalaciones. Es significativo que se cuente con cerca de 900 promotores voluntarios de salud, y 1400 parteras también voluntarias. Con base en las cifras oficiales, los indicadores son los siguientes: 0.05 médicos, 0.04 enfermeras profesionales y 0.11 en la oferta de servicios médicos por cada 1,000 habitantes.

Entre las causas de morbilidad más frecuentes, en el caso de las mujeres, están las complicaciones prenatales y perinatales, enfermedades respiratorias, parasitosis intestinal, diarreas agudas, puerperio fisiológico, amibiasis intestinal y parasitosis. En los hombres, las causas son enfermedades respiratorias agudas, diarreas agudas, parasitosis y amibiasis intestinales, faringoamigdalitis, dermatitis alérgica $y$ neumonía.

En cuanto a la mortalidad neonatal, para finales de los ochenta era de 20 por cada 1000 nacidos 
vivos y registrados, y la mortalidad posnatal era de 40 también por cada $1000 \mathrm{NVR}^{12}$. Más preocupante es que de cada 1,000 menores de 5 años, morían 160. La tasa de mortalidad infantil es fuertemente afectada por las condiciones sanitarias de la vivienda, las condiciones de vida en general y el grado de instrucción de la madre en materia de salud, higiene y alimentación. Además, cabe señalar que sólo 19 por ciento de los partos son atendidos en centros hospitalarios y 77 por ciento por parteras, la mayor parte empíricas. Además aproximadamente el 50 por ciento de la mortalidad materna se debe a hemoragias y 20 por ciento a sepsis. Como resultado se tienen, para 1991, las siguientes tasas: la mortalidad neonatal es de 8.06 por ciento; la posnatal, de 22.32; la infantil, de 30.28 por ciento; la materna de 1.18 por ciento, y la general de 5.52 por ciento. Entre las causas de muerte, las más frecuentes han sido enfermedades infecciosas intestinales, desnutrición, afecciones originadas en período perinatal, enfermedades del aparato respiratorio, enfermedades bacterianas, infecciones y parasitarias.

Lo anterior lleva a concluir que existe una oferta gubernamental de atención a la salud limitada y deficiente, donde la participación de redes sociales (vía organismos no gubernamentales y prácticas tradicionales) tiene un papel importante dado que absorbe gran parte de la demanda de atención de la población de Huehuetenango. Si bien esto lleva a un fuerte subregistro en morbilidad y mortalidad, lo grave es que las tasas de enfermedad y muerte son abatibles si se contara con la atención y los servicios oportunos. Es decir, hay una fuerte incidencia de las enfermedades y muertes de la pobreza en una población mayoritariamente indígena, analfabeta, joven, desempleada, con precarias condiciones de vivienda, alimentación, y en el acceso al empleo y a los servicios públicos asistenciales. Este es el perfil de la población que por lapsos se ve obligada a migrar, mucha de ella a México, a los cultivos ya antes mencionados. Con ese perfil, agregado a la condición de indocumentación en que se encuentran los migrantes, es previsible que existan pocas posibilidades de que los trabajadores agrícolas demanden atención a su salud en el país de destino y que, de llegar a enfermarse, recurran con mayor facilidad a la automedicación o las prácticas y redes sociales similares a las de su lugar de origen. Como se ve, son diversos y complejos los nutrientes de la indefensión del trabajador guatemalteco, incluso, antes de llegar a su destino laboral en México.

\section{La salud de los trabajadores guatemaltecos en la región fronteriza sur de México}

En la región fronteriza de Chiapas, el 80 por ciento de los pobladores usa leña para cocinar, mucho más de lo que registra el nivel nacional. En la contraparte guatemalteca, la proporción es del 90 por ciento, por lo que tanto en un país como en otro, la población expuesta a este tipo de contaminación, particularmente mujeres y niños, sufren padecimientos con mayor frecuencia de las vías respiratorias. Por tanto, los trabajadores migrantes, durante su estadía en México, no les resulta ajeno este tipo de contaminación que afecta sus vías respiratorias, prácticamente igual en uno y otro lado de la frontera. En particular, esto es válido para los trabajadores que son contratados por ejidatarios, pues al dormir en casa de éstos, lo hacen en la cocina o sus inmediaciones.

La tuberculosis es una enfermedad que predomina en la región con tasas muy altas (15.51), el doble de la escala nacional. La tuberculosis registra mayor número de casos en municipios fronterizos con Guatemala, lo que coincide con lo que ocurre en localidades de Huehuetenango, aunque en esos poblados la tendencia en el número de casos ha seguido en ascenso mientras que desciende en el lado mexicano. No se descarta que los frecuentes contactos, vía migración laboral, entre pobladores de uno y otro lado disemine el mal, aunque parece que los servicios de salud han tenido mejores resultados en territorio mexicano. En todo caso, la inexistencia de una política de salud uniforme y coordinada en ambos lados de la frontera y los frecuentes intercambios poblacionales hacen que las medidas sanitarias tomadas en un país sean de corto alcance, manteniéndose, en conjunto, tasas relativamente altas de esta enfermedad.

Otras dos enfermedades que afectan por igual a pobladores avecindados en ambos lados de la línea limítrofe, incluyendo a trabajadores temporales en México, son la oncocercosis y el paludismo. La

12. NVR significa nacidos vivos y registrados. 
primera, que afecta los órganos visuales, tiene su foco de infección más importante en el Soconusco, concretamente en Tapachula, el principal municipio productor de café en Chiapas y que emplea el mayor volumen de trabajadores guatemaltecos en la cosecha del grano. El paludismo, por su parte, tiene efectos similares en poblaciones asentadas a lo largo de la frontera y con migraciones laborales cíclicas. Los datos, empero, no permiten establecer una relación temporal entre migración y auge de la enfermedad, aunque personal de salud de México, con base en su experiencia laboral, asevera que tal relación existe. Dados los antecedentes, pareciera que trabajadores guatemaltecos y acompañantes enferman de oncocercosis durante su estadía laboral en Tapachula y retornan a Huehuetenango portando (o abiertamente enfermos) dicho mal. Sin embargo, en el caso del sarampión no puede sefialarse punto de origen, lo que es punto de controversia entre las autoridades sanitarias de ambos países. A final de cuentas, sin dejar de valorar el precisar el punto de origen, es menester una política sanitaria regional, sin contratiempos prácticos debido a jurisdicciones fronterizas, que atienda a la población expuesta o enferma del sarampión. Respecto' a la oncocercosis no hay duda sobre el lugar de origen, lo que ha fracasado son las medidas tomadas en contra de ella.

Las plantaciones de café, caña y plátano no cuentan con servicios sanitarios con capacidad suficiente para eliminar adecuadamente las aguas negras del total de sus trabajadores;-no tienen drenaje ni fosas sépticas para cientos de laborantes (sólo hay algunas de estas últimas de acceso y capacidad limitados). Por otro lado, tampoco existe, entre la gran mayoría de los empleados, el hábito de utilizar dichos servicios si los hubiera. En concecuencia, las excretas quedan expuestas al ras de suelo en terrenos con clima húmedo y cálido, con frecuentes lluvias, aguas que desembocan en riachuelos que se utilizan para proveerse del vital líquido para cocinar y beber durante las largas jornadas de trabajo. Así, las diarreas y enfermedades gastrointestinales son frecuentes entre la masa trabajadora de las plantaciones aludidas.

Cabe mencionar la elevada proporción de muertes por accidentes que, si bien no entra en el rubro de enfermedades, sí da una idea más global del perfil de las causas de mortalidad en el estado de Chiapas. La muerte por accidentes ocupa el segundo lugar dentro del grupo total de causas. Mu- chas de estas muertes se deben a la falta de asistencia médica cuando ocurren los accidentes (por la lejanía del centro médico o la escasez de los recursos médicos necesarios para atenderlos), los cuales se originan frecuentemente en el campo laboral; no en vano es la primera causa de muerte de gente en edad productiva y en mayores proporciones a las que se dan a nivel nacional. En particular, en los cultivos de caña y plátano, la utilización de herramientas punzocortantes y la utilización de ciertas fases tecnificadas en largas jornadas de trabajo provocan cansancio, lo cual favorece los accidentes. También la presencia de animales venenosos (serpientes y arácnidos) en los campos de cultivo exponen a los trabajadores a mordeduras y picaduras que pueden ser mortales. Lamentablemente para nuestro interés, no ha sido posible hacer una diferenciación por nacionalidad en los registros gubernamentales para tener una idea más exacta de lo que ocurre con la mano de obra migrante, aunque testimonios de campo indican una proporción nada despreciable.

Por otra parte hay que considerar el factor temor. Esto es, el trabajador extranjero se sabe vulnerable, y lo es, por tanto cuida que de enfermarse no sea descubierto por el capataz, el administrador o por el mismo patrón. Esto obedece a que puede ser despedido, no porque baje su productividad, ya que le pagan por el trabajo realizado, sino porque puede contagiar a otros; puede propagarse la noticia; ocasionar que otros trabajadores prefieran poner tierra de por medio antes de contagiarse y afectar el ritmo de cosecha; en fin, puede llamar la atención de las autoridades sanitarias, lo cual le podría ocasionar un problema al empleador. Nadie, por supuesto, habla de este temor: se lleva en la piel. Por eso el subregistro gubernamental de la morbilidad; la automedicación, el recurso de las añejas prácticas que cultural, económica y socialmente han estado a su alcance; la respuesta del trabajador enfermo es desde su pasado, desde su cultura y no desde su derecho ciudadano, que mal conoce y menos le sirve. Y, por otro lado, frente a la ausencia de la protección sindical, tiene la vigencia del colectivismo precapitalista: el médico tradicional, el yerbero, el huesero, la partera empírica. No es una contradicción, se trata de una adecuación de formas pasadas a requerimientos de sobrevivencia del presente.

\section{Un problema de salud más allá de las fronteras}

Es indudable que los gobierno de México y Gua- 
temala tienen un serio problema de salud pública en la región limítrofe con poblaciones cultural, social y económicamente interrelacionadas ${ }^{1 ?}$. Los cuadros epidemiológicos de poblaciones vecinas de Chiapas (México) y Huehuetenango (Guatemala) son bastante similares como para invitar al diseño de un plan binacional de salud pública que, sin negar las responsabilidades de cada país, potencie recursos humanos, técnicos y materiales para contrarrestar enfermedades y muertes evitables que han demostrado no regirse por las fronteras jurídicas nacionales.

En lo que se refiere a la salud de los trabajadores guatemaltecos en México, se puede avanzar mediante un esquema específico de atención para ellos. Es altamente posible que con realizar consultas previas con los sectores contratantes se apliquen medidas de corte gradual, dado que no todos los empleadores verían con buenos ojos una intromisión gubernamental en aspectos contractuales que hasta ahora han sido de su exclusivo dominio. El peso económico de los empleadores en la economía nacional puede hacer vulnerables o inviables los posibles intentos gubernamentales de regular relaciones contractuales conforme a derecho, si no se cuidan formas y tiempo de los sectores económicos locales. Se necesita de su colaboración para introducir modificaciones en el esquema actual de salud en beneficio de los trabajadores en particular, y de la población en general. Es de desear que Guatemala, por su parte, avance en los programas de atención a la salud. Mas, dada la crítica situación que caracteriza su sistema de creación y distribución de la riqueza social, es poco previsible que se mejoren las condiciones de vida de los sectores sociales mayoritarios.

La acción independiente y, en algunas actividades, conjunta de los gobiernos es necesaria, pero no suficiente. Las sociedades mismas tienen su cuota de responsabilidad, que hasta el momento la han cubierto con prácticas curativas tradicionales, que no siempre resultan exitosas, con el consiguiente resultado de agravamiento o muerte del enfermo. Podría decirse que son muchas las carencias y las demandas y pocos los recursos y conocimientos espe- cíficos de las poblaciones involucradas, lo cual no deja de ser parcialmente cierto. En todo caso, pareciera mantenerse como necesidad constante, para empezar y hasta concluir, unos ingredientes básicos: voluntad politica de los gobiernos, capacidad para concitar a la sociedad, respeto a y entre los sectores sociales involucrados y un alto sentido de respeto de los derechos de los ciudadanos, migrantes o no, que no debieran demeritarse ante la concurrencia de diferentes nacionalidades y culturas en las relaciones contractuales.

\section{Bibliografia}

Arana, M. Educación y gestión ambiental en la selva de Chiapas. Centro de capacitación en ecología y salud para campesinos, Instituto Nacional de la Nutrición "Salvador Zubirán" (doc. Mimeo), 1987.

Arana, M. "La salud en Chiapas al fin de siglo", en Salud, crisis y fin de siglo, Siglo XXI, México, 1989.

Arana, M. "La salud en el municipio de Las Margaritas, Chis.", Escuela de Salud Pública de México, (reporte lécnico), Mimeo, 1984.

Ayala RHS. "Cultura, demografía y políticas de población en México (notas para un diálogo interdisciplinario)", Universidad Nacional Autónoma de México, octubre, 1992.

Ballinas, J. "El desierto de los lacandones", Ateneo de ciencias y artes de Chiapas. Tuxtla Gtz. Chis, 1951.

Bentham G. "Migration and Morbidily: Implications for Geographical Studies of Disease”, Soc Sci Med, Vol 26, No 1, 1988, pp. 49-54.

Buelher J., Frey R. y Chu S. "The Migration of Persons with AIDS: Data from 12 States, 1985 to 1992", Amer I Public Healih, Vol 85, No 11, 1552:1555, 1995.

Bringas H. H. Las políticas de salud y la mortalidad en México; políticas de población en México; un acercamiento a sus planteamientos y efectos; Universidad Nacional Autónoma de México, octubre, 1992, pp. 147-179.

Casillas R. y López S. "Un acertijo de nuestros días: esquemas de salud para poblaciones migrantes", versión final de la ponencia presentada en el IV Congreso Latinoamericano de Ciencias Sociales y Medicina. Cocoyoc, México, junio. 1997.

Casillas, R. y Castillo M. A. Los flujos migratorios internacionales én la frontera sur de México. México, 1994, Secretaría del Trabajo y Previsión Social-Con-

13. Ciertamente, ha habido en el pasado reciente esfuerzos limitados y truncos por varias razones, pero la magnitud y complejidad de los procesos migratorios y su creciente interrelación con localidades diversas urgen el diseño de nuevos esquemas de atención a la salud de las poblaciones móviles. 
sejo Nacional de Población, p. 248.

Casillas, R. y Vicente M. La frontera sur: un mosaico sanitario, México, Secretaría de Salud, 1994.

CIES. "Perfil epidemiológico y grados de marginación", Chiapas, Cuaderno de trabajo No 1, San Cristóbal de las Casas, Chiapas. Centro de Investigaciones Ecológicas del Sureste, 1994.

Figueroa, J. et al. "Trabajo femenino y salud en la infancia en tres regiones (Informe de Resultados)". Dirección General de Planificación Familiar, Secretaría de Salud, 1992.

Fondo de las Naciones Unidas para la Infancia. "Areas críticas en Chiapas: diagnóstico y lineamientos para una estrategia", UNICEF, México, 1984.

Instituto Mexicano del Seguro Social. Convenio IMSSUnión Regional de Productores de café Tacaná, Tapachula, Chiapas, 1992.

Krasnik A. "The Concept of Equity in Health Services Research", Scandinavian Journal Of Social Medicine, Scandinavian University Pres, Vol. 24, No 1, marzo, 1996.

López-Moreno S., Castro A.J.M., Ordufia V.A. "Perfil epidemiologico de los campesinos de las Margaritas", Chis., Secretaría de Salud, Comitán, Chis., 1985.

Mier y Terán, M. "Patrón de alimentación temprana y salud de los niños en México", Conferencia Mundial Sobre la Encuesta Demográfica y de Salud, Washington, 1991.

Moreno-Altamirano L. y cols. "Encuesta de salud de los refugiados guatemaltecos en la frontera sur de México", Bol of Sanit Panam, Vol. 103, No 3, 1987, pp. 233-243.
Novacovsky Y. y López N. Salud y pobreza; el acceso difrencial al sistema de atención. Ciencias Sociales y Medicina, Ed. Universitaria, agosto, 1992.

Organización Panamericana de la Salud. "Rasgos epidemiológicos de la tuberculosis en el mundo", Bol Of Sanit Panam, Vol. 119, No 6, 1995, pp. 529-30.

Paikin, S.M., Prece G., Necchi S. y Adamo M.T. "Estrategias familiares frente a la salud", Ciencias Sociales y Medicina, Ed. Universitaria, agosto, 1992.

Pérez Tamayo, R. Enfermedades viejas y Enfermedades Nuevas, Ed. Siglo XXI, México, 1985.

Pick J.B., Tellis G.L., Butler E.W. y Paugi S. "Determinantes socioeconómicos de migración en México", Estudios Demográficos y Urbanos, No 13, El Colegio de México, Vol. 5, No I, enero-abril, 1990, pp. 61-101.

Reid D.D. "International Studies in Epidemiology", Am J Epidemiol, Vol. 141, No 10:888895, 1995.

Simmons, Alan B. "Explicando la migración: la teoría de la encrucijada", Estudios demográficos y Urbanos, Vol. 6, No 1, enero-abril, 1991, p. 5-31; 36.

Slesinger D. y Christenson B. "Health and Mortality of Migrant Farm Children", Soc Sci Med, Vol. 23, No I, 1966, pp. 65-74.

Takehiro, Misawa e Ixtacuy: Octavio "El efecto del empleo matemo sobre el crecimiento de los niños según edad de los niños: la zona de producción platanera en Chiapas", V Reunión Nacional de Investigación Demográfica en México, Sociedad Mexicana de Demografía, 1994.

Rodolfo Casillas R. 